\title{
IMPROVING PUPIL PERFORMANCE IN ENGLISH SECONDARY SCHOOLS: EXCELLENCE IN CITIES
}

\author{
Stephen Machin \\ University College \\ London and London \\ School of Economics
}

\author{
Sandra McNally \\ London School of Economics \\ Costas Meghir \\ University College London and IFS
}

\begin{abstract}
This paper reports on the short run impact of one of the U.K. government's flagship education policies, the Excellence in Cities (EiC) program. EiC is aimed specifically at alleviating poor student achievement in inner city areas. The analysis compares educational attainment in Maths and English for Year 9 (age 14) students before and after EiC introduction in EiC schools as compared to non-EiC schools. School-level absences in treatment and control schools are also compared. The results show a positive, though small, improvement in pupil attainment and a strong reduction in absences within EiC schools relative to schools in the comparison group. We interpret the findings as evidence that policies like EiC can impact positively on pupil attainment and attendance. (JEL: I21, H52, C52)
\end{abstract}

\section{Introduction}

The current U.K. government has claimed repeatedly that education forms a vital part of its policy agenda. An important aspect of this has been an explicit attempt to turn around the fortunes of badly performing schools in the inner cities (West and Pennell 2003). In this paper, we focus on some of the first findings from our evaluation of one of the flagship policies that the government has introduced, the "Excellence in Cities" (EiC) program. This is a wellpublicized program aimed specifically at alleviating underachievement in inner city schools within England.

EiC was launched in 1999 for over 400 secondary schools and has quickly been extended to cover more schools and to primary and postcompulsory phases

\footnotetext{
Acknowledgments: This work was funded by the Department for Education and Skills. We are grateful for comments and suggestions to a large number of seminar participants and other members of the Excellence in Cities consortium. We would particularly like to thank Mike Treadaway of the Fischer Trust for provision of the pupil-level data sets we use and for much helpful advice.

E-mail addresses: Machin: s.machin@ucl.ac.uk; McNally: s.mcnally1@1se.ac.uk; Meghir: c.meghir@ucl.ac.uk
} 
of education. By 2003, the program covered about a third of secondary school pupils. In the 2002-2003 financial year the resources devoted to the scheme were about $£ 300$ million, and this is set to more than double to $£ 700$ million by 2006. Early press reports suggest that the policy has been highly successful, but do not reach this verdict based upon rigorous analysis or policy evaluation. In this paper we present some first findings of the short-run impact of the EiC program.

Our work is important in an academic context when one observes the growing amount of research attention placed upon government interventions in education in recent years. In the United States, for example, a lot of work has looked at specific interventions, paying particular attention to the statistical design of the evaluation. Some recent examples of this are the Tennessee STAR class size experiments (Krueger 1999, Krueger and Whitmore 2001) and the New York City school choice program (Krueger and Zhu 2003). There is less work for other countries, though some exists such as Angrist and Lavy's (2002) study of the Israeli high school matriculation exam, the Bagrut. Other work, not based upon experimental evidence, tries to mimic government interventions by looking for "natural experiments" created by policy, probably the most famous being the exploitation of class size rules, again in the Israeli school system, studied by Angrist and Lavy (1999).

In our work, we apply a difference-in-differences approach combined with matching (see Heckman, Ichimura, and Todd 1997, or Blundell et al. 2002) to evaluate whether student attainment in Maths and English has improved as a result of EiC. Thus, we compare average outcomes in treatment and comparison groups before and after the introduction of the policy. We also control for the student's prior attainment and a wide range of controls for the characteristics of secondary and primary schools that were attended by these students.

In this initial evaluation, we mainly focus on student attainment at age 14. This is two years before students sit their examinations for GCSE (the General Certificate of Secondary Education), at the end of their compulsory education. ${ }^{1}$ Attainment at this stage of education (Key Stage 3) attracts considerable policy attention. For Maths and English the target is that by 2004, $75 \%$ of 14-year-olds reach "Level 5", which is defined as the expected level for their age. In 2001, about $60 \%$ of students reached this Key Stage 3 level in Maths and English in $\mathrm{EiC}$ areas, as compared to about $70 \%$ of students in the rest of the country. An important research question for policy is whether EiC can help to close the gap.

We also look at the impact of EiC on school-level absences. The government has targets set in relation to truancy and exclusions-every secondary school and Local Education Authority has been given a target. The hypothesized

1. Data constraints prevent us looking at GCSE performance in this paper, but this is on the agenda for future research. 
link between truancy/exclusions and youth crime has made this issue very high-profile, especially within deprived areas, many of which are targeted by the EiC program. Hence, we consider the effect of EiC on school absence rates.

The outline of the rest of the paper is as follows. In Section 2, we briefly outline how the EiC program operates and when it was introduced in different areas. In Section 3, we describe our data sources, how comparison groups are defined and report a simple descriptive analysis of changes over time in attainment and absences for schools in the treatment and comparison groups. Section 4 first explains how the EiC impact is estimated by outlining the modeling approach, before moving on to report results which focus on the impact of $\mathrm{EiC}$ on attainment and absences from difference-in-difference statistical models. Finally, in Section 5 we make some concluding comments.

\section{The Excellence in Cities Program}

\subsection{Brief Description of Program and its Stated Aims}

Since the launch of Excellence in Cities in 1999 (at the start of the 1999-2000 school year), resources have been mainly targeted at secondary schools (through Local Education Authorities) in disadvantaged urban areas of England. The policy continues to be extended geographically and to cover students at different stages of education. It now includes primary schools and measures to encourage postcompulsory education. In this paper, we focus on the impact of Excellence in Cities $(\mathrm{EiC})$ on exam attainment in secondary schools (where pupils are aged 11-16) and on school-level absences (or attendance).

The program includes a number of different strands aimed at extending learning opportunities and tackling barriers to learning. There are separate strands directed at lower- and higher-ability students, respectively, as well as strands directed at encouraging particular types of school (e.g., Specialist schools in particular subject areas) and cooperation between schools in the dissemination of knowledge. Specifically, there are three core strands of EiC that affect all schools in treatment areas: Learning Mentors, to help students overcome educational or behavioral problems; Learning Support Units, to provide short-term teaching and support programs for difficult pupils; and a Gifted and Talented program, to provide extra support for 5-10\% of pupils in

each school. Within EiC areas, there is provision to designate more schools as Specialist (i.e., in particular subjects) or Beacon (to disseminate good practice), for which substantial sums of money are provided to particular schools that are successful in applying for these funds. Other components of EiC are City Learning Centers (to provide ICT facilities) and Education Action Zones (where sharing of good practice is also emphasized). 
In practice, the way in which EiC resources are allocated varies by Local Education Authority-though it is strongly linked to pupil numbers and the degree of disadvantage in the school (as measured by the proportion of pupils eligible for Free School Meals). Also, the way in which individual strands are implemented varies greatly between schools. In this paper, we focus on the combined impact of this range of measures on pupil performance at age 14 and on school-level absences.

\subsection{Introduction of EiC}

The EiC policy operates within Partnerships of Local Education Authorities (LEAs) and LEA maintained schools within their respective regions. In September 1999, EiC began in 24 Partnerships (known as Phase 1), covering 440 secondary schools. The policy started within a further 23 Partnerships (i.e., Phase 2) in September 2000, which added another 315 schools. Schools in these partnerships form the treatment group in our analysis. ${ }^{2}$ The approach we follow is therefore to compare children in schools exposed to EiC with those in schools that did not receive resources from the program. Our empirical work attempts to look at the short-run impact of the program by considering attainment and school absences before and after EiC introduction (in 1999 and 2001) in schools affected by the policy as compared to those not in the program.

\section{Data Description}

\subsection{Data Sources}

The empirical analysis is based upon administrative records of pupil-level attainment and school-level data. The former consists of a matched data set of all English secondary school students who were in Year 9 (the Key Stage 3 testing year) in either 2001 or 1999, together with their Key Stage 2 results (taken in primary school, three years previously). ${ }^{3}$ Only nonspecial schools that are LEA maintained are included in the analysis. This excludes schools that exist exclusively for students with special needs, all independent schools and City Technology Colleges. ${ }^{4}$

2. A further round of EiC started in September 2001 (i.e., "Phase 3"). These schools are not in the treatment group over the period in which we are measuring outcomes.

3. The years referred to in the empirical work are the years in which testing takes place. For example, the pre-policy year 1999 refers the 1998-1999 school year since pupils are tested at the end of the school year.

4. Independent schools are not covered by the EiC policy. There are only fourteen City Technology Colleges in our data set. In some cases, it is not clear whether or not they are part of 


\subsection{Defining a Comparison Group}

Our methodology involves comparing performance measures for "treatment" (subject to the EiC policy) schools with schools in different comparison groups. The first comparison group is defined simply as all schools in the data set that are not in Phase 1 or Phase 2 of EiC. The second comparison group is based on a group of schools that were selected to participate in a series of interviews as part of the evaluation of EiC. This sample of survey comparison group schools was based on LEA maintained schools outside the EiC Phase 1 and Phase 2 LEAs. Within this subset of schools, a sample was drawn and weighted by the proportion of students eligible for Free School Meals so as to replicate this distribution within EiC schools. This ensures that the comparison group is similar in terms of disadvantage to the EiC schools. Further measures were taken to ensure that Beacon and Specialist schools are adequately represented in the "survey comparison" group.

\subsection{Descriptive Analysis}

Table 1 shows summary statistics for Key Stage 3 attainment in Maths and English and school absences for EiC schools, the survey comparison group and all schools that are not in Phase 1 or Phase 2 of EiC. The average attainment level in each subject and the school absence rate is shown for 1999 and 2001, as well as the change between the two years.

Because of the nature of the testing system, we report the average level attained in the case of Maths and the percentile score achieved for English. The latter is possible because all students are assessed on the same metric in English, whereas in Maths, testing is more complex and we can only consider Key Stage levels. $^{5}$

Table 1 shows a bigger improvement in the average Maths and English performance of EiC pupils relative to the comparison groups. For example, the average level of attainment in Maths rises by 0.18 (from 4.75 to 4.93 ) for EiC pupils, but by 0.14 (from 4.78 to 4.92 ) in the survey control schools and by 0.16 (from 5.19 to 5.35) in all secondary schools not in EiC. There is also an improvement in English attainment for pupils affected by EiC. The middle panel of Table 1 shows that the average percentile in Key Stage 3 English performance increases by 0.62 of a percentile, as compared to a fall in the non-EiC schools. Turning to absences, the group of EiC schools is the only one where

the EiC policy. But they are quite different from other maintained schools in the data set as they are not maintained by Local Education Authorities.

5. The situation is more complicated for Maths, where there are four possible sets of exams corresponding to different entry tiers. In Machin, McNally, and Meghir (2003) we discuss this in more detail and also consider whether EiC had an impact on entry into different tiers. We find little such effect for Key Stage 3 Maths in 2001. 
TABLE 1. Descriptive statistics on Key Stage 3 attainment and absences

\begin{tabular}{lccr}
\hline & $\begin{array}{c}\text { Treatment group: } \\
\text { EiC Phase 1 and } \\
\text { EiC Phase 2 }\end{array}$ & $\begin{array}{c}\text { All schools not } \\
\text { in EiC Phase 1 } \\
\text { or EiC Phase 2 }\end{array}$ & $\begin{array}{c}\text { Comparison } \\
\text { group }\end{array}$ \\
\hline KS3 Maths: Average level & & & \\
1999 & 4.75 & 5.19 & 4.78 \\
2001 & 4.93 & 5.35 & 4.92 \\
Change, 1999 to 2001 & 0.18 & 0.16 & 0.14 \\
Number of pupils & 240,884 & 817,434 & 44,681 \\
Number of schools & 699 & 2,390 & 143 \\
KS3 English: Average percentile & & & \\
1999 & 44.05 & 51.26 & 42.98 \\
2001 & 44.67 & 51.20 & -0.51 \\
Change, 1999 to 2001 & 0.62 & -0.06 & 44,646 \\
Number of pupils & 241,789 & 817,889 & 143 \\
Number of schools & 699 & 2,390 & 10.54 \\
Absences: Percent half-days missed in school & & 0.15 \\
1999 & 10.42 & 8.60 & 143 \\
2001 & 10.38 & 8.85 & 0.25 \\
Change, 1999 to 2001 & -0.04 & 2,349 & \\
Number of schools & 699 & & \\
\hline
\end{tabular}

Notes: KS3 levels calculated from pupil-level administrative data on Key Stage 3 examination results; absences calculated from school-level data from the Secondary School Performance Tables.

absences decline. Hence this is suggestive of a positive EiC effect on school attendance.

\section{Estimating the Impact of EiC}

\subsection{Modeling Approach}

Our modeling approach involves a comparison of each outcome variable in EiC schools with that in the control groups before and after the introduction of EiC, while attempting to take account of factors other than EiC that may explain any outcome difference. For some models we combine this with matching at a prior step to ensure that comparison schools are sufficiently similar to treated schools. The empirical specification we use to implement this difference-in-difference approach for attainment measure $P$ of pupil $i$ in secondary school $s$ in a particular time period $t$ is:

$$
P_{i s t}=\alpha_{s}+\beta \mathrm{EiC}^{*} D_{t=q}+\gamma X_{i s t}+\delta Z_{s t}+\lambda P_{i s, t-1}+\alpha_{t}+\varepsilon_{i s t}
$$

where EiC is a school-level dummy variable, indicating whether the school is an EiC school, $D_{t=q}$ is a dummy variable equal to one for time periods after the 
policy was introduced (here $t=q$ ), $X$ denotes pupil characteristics, $Z$ is a set of school characteristics and $\varepsilon$ is an error term. The $\alpha_{\mathrm{s}}$ term in the model is a set of secondary school dummy variables, included so as to control for unobserved school characteristics that may differ across EiC and non-EiC schools. The $\alpha_{\mathrm{t}}$ term is a set of year dummies, included to capture year-on-year differences in pupil attainment. The model also contains a lagged dependent variable measuring pupil attainment in an earlier time period, $t-1$ (in practice this is Key Stage 2 performance at the end of primary school).

The principal parameter of interest in equation (1) is $\beta$, the difference-indifference estimate, which captures shifts in the outcome measure within treatment schools vis-à-vis control schools that occur after the policy is introduced. Notice that when school fixed effects are included we are not able to identify a levels (i.e., baseline, prepolicy) EiC effect as it is subsumed into the school fixed effects and hence no EiC dummy appears in Equation (1). The policy impact is identified through the time interaction.

\subsection{Attainment Results}

We present statistical estimates of the impact of EiC introduction for Maths in the upper panel of Table 2. Three estimates of equation (1) are reported, each of which focuses on different samples. In column (1) the control group is all non-EiC schools from administrative data and in column (2) it is the survey comparison group, as described previously. In column (3) we use statistical matching methods to remove schools that look very different on the basis of prepolicy characteristics (see Machin, McNally and Meghir 2003, for more details).

A clear pattern emerges, with a significant, positive EiC policy effect on Maths attainment. The statistical modelling shows an improvement in Maths of about 0.03 of a level for pupils in EiC schools. The effects are reassuringly robust across the different specifications reported in Table 2. An intuitive way to interpret the coefficient is that the average effect of $\mathrm{EiC}$ is to increase the number of pupils moving up one level by about $3 \%$. Results are also positive, but weaker in statistical terms (especially for the smaller sample in column 2), for English. The average policy impact is of the order of 0.5 to 0.8 of a percentile.

Hence we have some evidence of short-run (one year) improvements in Key Stage 3 attainment, though the effects are rather moderate in magnitude. The attainment of pupils in schools exposed to EiC seems to have improved relative to the prepolicy period, when this is benchmarked against the change over the same period in non-EiC schools. 
TABle 2. EiC and Key Stage 3 attainment

\section{Maths Key Stage 3 level}

(2)

(1)

Controls: all

other schools

$0.025(0.007)$

$1,058,318$

3,089

0.69
(3)

Controls: all

other schools,

comparison matching

$0.033(0.008)$

932,777

2,626

0.70

English Key Stage 3 percentiles

(5)

Controls:

comparison group

0.67
(4)

Controls: all other schools
$\mathrm{EiC} *$ Year $=2001$

Number of pupils

Number of schools

$R^{2}$
$0.553(0.387)$

$1,059,678$

3,089

0.62
(6)

Controls: all other schools, matching

$0.510(0.408)$

934,014

2,626

0.62

Notes: Robust standard errors in parentheses (clustered on secondary schools). All specifications include gender, prior attainment at age 11, a year dummy, school fixed effects and a range of variables relevant to the pupil's secondary school and primary school: number of pupils; pupil-teacher ratio; percentage of pupils with special educational needs (with/without statement); percentage of pupils eligible for Free School Meals; percentage of non-White pupils; average performance of primary school (in terms of absences; attainment) at the time when it was attended by the pupil; average performance of secondary school in the prepolicy period (in terms of absences; attainment) dummies for the following: all boys school; all girls school; religious school; in rural area; sixth form (secondary); non-EiC specialist school (secondary); grammar school (secondary); primary school type (infant; independent; special; other); missing value dummies.

\subsection{Absence Results}

Table 3 shows results for school-level absences, again in a difference-indifference setting. The dependent variable is the percentage of half days missed by pupils in the school. As with the earlier regressions, three specifications are reported. The estimated policy impact is negative and sizeable, at -0.3 to -0.4 .

TABLE 3. EiC and school absences

\begin{tabular}{lcrr}
\hline & Absences & \\
\cline { 2 - 4 } & & $(2)$ & $(3)$ \\
& $(1)$ & Controls: & Controls: all \\
& Controls: all & comparison & other schools, \\
& other schools & group & matching \\
\hline EiC $*$ Year $=2001$ & $-0.370(.111)$ & $-0.300(.236)$ & $-0.308(.112)$ \\
Number of schools & 3,048 & 842 & 2,626 \\
$R^{2}$ & 0.93 & 0.93 & 0.93 \\
\hline
\end{tabular}

Notes: The dependent variable is the absence rate, namely the percentage of half-days missed in school; robust standard errors in parentheses (clustered on secondary schools). All specifications include school fixed effects and the average (school-level) values of the variables listed in the notes to Table 2. 
This shows a significant reduction in absences, or alternatively, a significant improvement in attendance for EiC schools after the policy was introduced.

\subsection{Gender Differences in EiC Impact}

The evidence reported to date shows an improvement in attainment (albeit fairly modest) and absence reductions for pupils exposed to $\mathrm{EiC}$ as compared to those attending non-EiC schools. We have also explored some variations around the average impact. Table 4 reports on one example, showing gender differences in the EiC impact. Specifically, estimates of the EiC effect on Key Stage 3 Maths and English are shown for boys and girls separately. This is an interesting exercise due to the presence of gender gaps in attainment-in favor of girls-in English secondary schools (see, among many others, Machin and McNally 2003 or West and Pennell 2003). The estimates for Maths attainment show larger effects for boys than for girls. For boys exposed to EiC, there is an improvement of just under 0.04 of a level for KS3 Maths attainment as compared to just over 0.01 for girls. In English, however, there is no gender difference in the EiC impact.

\section{Concluding Remarks}

Excellence in Cities is an important component of the U.K. government's drive to improve attainment within poorly performing inner-city schools in England. Substantial resources are being invested for this purpose. The aim of this paper is to provide a preliminary evaluation of how successful the policy has been in the short run in improving attainment in Maths and English for 14-year-old children and in raising school attendance.

Our results show a positive EiC impact on pupil performance (particularly in Maths), although the magnitudes of the estimated effects are modest. There is strong evidence that absences were reduced relative to schools not in the EiC

TABle 4. EiC and Key Stage 3 attainment, gender differences

\begin{tabular}{|c|c|c|c|c|}
\hline & \multicolumn{2}{|c|}{ Maths Key Stage 3 level } & \multicolumn{2}{|c|}{ English Key Stage 3 percentiles } \\
\hline & $\begin{array}{c}\text { (1) } \\
\text { Boys, } \\
\text { controls: all } \\
\text { other schools }\end{array}$ & $\begin{array}{c}\text { (2) } \\
\text { Girls, } \\
\text { controls: all } \\
\text { other schools }\end{array}$ & $\begin{array}{c}(3) \\
\text { Boys, } \\
\text { controls: all } \\
\text { other schools }\end{array}$ & $\begin{array}{c}\text { (4) } \\
\text { Girls, } \\
\text { controls: all } \\
\text { other schools }\end{array}$ \\
\hline $\mathrm{EiC} *$ Year $=2001$ & $0.036(0.008)$ & $0.013(0.009)$ & $0.559(0.404)$ & $0.602(0.449)$ \\
\hline Number of pupils & 536,008 & 522,182 & 535,902 & 523,658 \\
\hline Number of schools & 2,890 & 2,927 & 2,889 & 2,928 \\
\hline$R^{2}$ & 0.70 & 0.69 & 0.61 & 0.61 \\
\hline
\end{tabular}

Notes: As for Table 2. 
program. However, it is important to note that these are only short run impacts. It may well be that the policy has potential to have a greater impact when it has been longer established in schools. This is on the agenda for our current and future research. Nonetheless, these first set of findings do show that education policies targeted at pupils in disadvantaged schools can have the desired effect of raising performance. The longer-term challenge is to assess whether economic benefits accrue to disadvantaged pupils in the EiC program. In doing so, it will be important to assess whether what is quite a costly policy will produce, as the government has hoped, longer-term benefits to outweigh, or at least to balance, these costs.

\section{References}

Angrist, Joshua and Victor Lavy (1999). “'Using Maimonides' Rule to Estimate the Effect of Class Size on Student Achievement." Quarterly Journal of Economics, 114, 533-576.

Angrist, Joshua and Victor Lavy (2002). "The Effect of High School Matriculation Awards: Evidence From Randomized Trials.” NBER Working Paper 9389.

Blundell, Richard, Monica Dias, Costas Meghir, and John van Reenen (2002). "Evaluating the Employment Impact of a Mandatory Job Search Assistance Program.” IFS Working Paper No. 01/20.

Heckman, James, Hidehiko Ichimura, and Petra Todd (1997). "Matching as an Econometric Evaluation Estimator.” Review of Economic Studies, 65, 261-294.

Krueger, Alan (1999). "Experimental Estimates of Education Production Functions." Quarterly Journal of Economics, 114, 497-532.

Krueger, Alan and Diane Whitmore (2001). "The Effect of Attending a Small Class in the Early Grades on College Test-Taking and Middle School Test Results: Evidence From Project STAR.” Economic Journal, 111, 1-28.

Krueger, Alan and Pei Zhu (2003). "Another Look at the New York City School Voucher Experiment." National Bureau of Economic Research Working Paper 9418.

Machin, Stephen and Sandra McNally (2003). "Gender and Educational Attainment." Working paper, Centre for Economics of Education, London School of Economics.

Machin, Stephen, Sandra McNally, and Costas Meghir (2003). "Excellence in Cities: Evaluation of an Education Policy in Disadvantaged Areas." Working paper, Department for Education and Skills.

West, Anne and Hazel Pennell (2003). Underachievement in Schools. Routledge Falmer. 